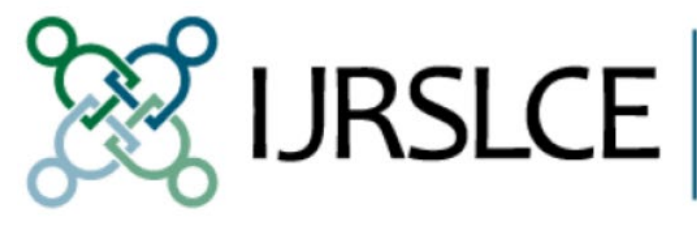

International Journal

for Research on

Service-Learning \&

Community Engagement

Volume 4 | Issue 1

Article 24

2016

\title{
Fostering Undergraduate Spiritual Growth Through Service-Learning
}

\section{Michelle Strek Barrett}

This article was originally published at:

https://journals.sfu.ca/iarslce/index.php/journal/article/view/188/175

Recommended Citation

Barrett, M. S. (2016). Fostering undergraduate spiritual growth through service-learning. International Journal of Research on Service-Learning and Community Engagement, 4(1), 291308. 


\title{
Fostering Undergraduate Spiritual Growth Through Service-Learning
}

\author{
Michelle Sterk Barrett \\ College of the Holy Cross
}

\begin{abstract}
Scholars and educational leaders have expressed concern that higher education is not adequately meeting students' desire for spiritual growth within an academic context. Prior studies have demonstrated a relationship between the pedagogical method of service-learning and spiritual development. This study analyzed the relationship between specific service-learning components and the occurrence of spiritual growth in an effort to better understand how such growth can be fostered within the curriculum. Findings indicated that spiritual growth occurred when students experienced significant challenge balanced with support. Challenge was initiated when students witnessed injustice while simultaneously being exposed to new, diverse perspectives in class. Support emerged from relationships as well as the effective integration of coursework with the service experience.
\end{abstract}

Studies have found that undergraduates, and youth in general, have an overwhelming interest in spirituality. Astin, Astin, and Lindholm (2004) discovered that 78\% of undergraduates discussed religion or spirituality with their friends. Roehlkepartain, Benson, Scales, Kimball, and Ebstyne-King (2008) investigated spiritual beliefs among 12- to 25-year-olds in eight countries and found that only $20 \%$ described themselves as not spiritual. Yet, students have expressed that higher education academic experiences are not meeting their desire for spiritual development (Astin et al., 2004; Chickering, Dalton, $\&$ Stamm, 2006; Kuh \& Gonyea, 2006). In Astin et al.'s (2004) research, 53\% of undergraduates reported that the classroom had no impact on their spiritual beliefs, and only $55 \%$ were satisfied with the experience their college provided for religious or spiritual reflection.

Higher education scholars have also expressed concern about the lack of emphasis on spirituality in the classroom (Astin, Astin, \& Lindholm, 2011b; Chickering, et al., 2006; Rendon, 2009). Chickering et al. (2006) stated that students, faculty, student affairs personnel, and campus leaders "have begun calling for an exploration of ways to better integrate students' search for meaning and their spiritual quests with their academic preparation in the classroom" (p. 2). Integrating opportunities for spiritual growth in the classroom also has the potential to lead to numerous personal and societal benefits that prior research has associated with spirituality, including increased psychological well-being (Astin, et al., 2011b; Park \& Millora, 2010), increased caring and compassion (Brandenberger \& Bowman, 2013), increased appreciation for diversity (Astin, et al., 2011b), decreased alcohol and substance abuse (Kuh \& Gonyea, 2006), less risky health behaviors (Nelms, Hutchins, Hutchins, \& Pursley, 2007) and increased success among ethnic minority students (Walker \& Dixon, 2002).

The ability to effectively facilitate spiritual development in the classroom, however, depends on one's understanding of how to foster spiritual growth pedagogically. As earlier studies have demonstrated, service-learning is one pedagogy that has shown promise in facilitating undergraduate spiritual development (Astin et al., 2011b; Cherry, De Berg, \& Porterfield, 2001; Eyler \& Giles, 1999; Kuh \& Gonyea, 2006; Lovik, 2010; Radecke, 2007; Yeh, 2010).

Eyler and Giles (1999) surveyed 1,136 students who participated in service-learning at 30 higher education institutions and found that $46 \%$ of students identified spiritual growth as a very important or the most important outcome of their service-learning experience. Kuh and Gonyea (2006) analyzed the National Survey of Student Engagement (NSSE) data gathered in 2004 from 149,801 students at 461 four-year colleges and universities and found that participation in service-learning correlated significantly with participation in spiritual practices and a deepened sense of spirituality. Lovik (2010) also analyzed 
2004 NSSE data from 7,000 first-year students at 450 institutions and found that the strongest predictor of spiritual growth among all curricular experiences was enrollment in a service-learning course. Radecke (2007) conducted a qualitative study with 44 undergraduates investigating their perceptions of the impact of a short-term international service-learning course on their spiritual lives and faith formation. He found that over half of the students stated specifically that the experience had led to a deepened religious faith. Students participating in Cherry et al.'s (2001) ethnographic study investigating religious life at a selected college consistently reported that service-learning "had given them the opportunity to undergo a process of personal transformation and spiritual growth" (p. 181). Yeh (2010) conducted a qualitative study with six service-learning participants at two colleges to investigate the question of whether service-learning can play a role in the retention of low-income, first-generation students. Although not the focus of the study, spiritual growth, Yeh concluded, was one of the primary areas of growth and development for study participants. Astin, et al. (2011b) conducted the most comprehensive study of college student spirituality and religiosity to date. Their College Students' Beliefs and Values (CSBV) survey was administered in 2004 to 112,232 entering students, and a sub-sample of 14,527 of these students took the CSBV during spring of their junior year. Results indicated that student participation in service-learning had powerful impacts on the spiritual quest, ethic of caring, and ecumenical worldview dimensions of spirituality.

While these seven studies demonstrated a clear relationship between service-learning and spiritual growth, no prior study has utilized a mixed-methods approach to investigate this relationship. Furthermore, only one of these studies (Radecke, 2007) investigated concepts of service-learning and spiritual growth simultaneously as a primary focus. Therefore, the current understanding of conditions likely to lead to spiritual growth through service-learning is limited.

\section{Theoretical Framework}

In examining college student development more broadly, Nevitt Sanford $(1962,1966,1967)$ proposed that optimal development occurs when students face an appropriate balance of challenge and support. Sanford proposed that individuals seek naturally to maintain internal equilibrium and that this equilibrium can be disrupted by challenging stimuli. When facing disequilibrium, one first attempts to use coping strategies that have previously been successful in reducing tension associated with such imbalance. However, when stimuli are so challenging that prior strategies are ineffective, a new and innovative response becomes necessary. Within the context of this innovation, the possibility for growth occurs. However, if a student is not adequately supported through this process, then the possibility for healthy growth may be hindered.

Sanford's $(1962,1966,1967)$ challenge and support theory aligns with spiritual development theories proposing that spiritual struggle is a necessary precursor to spiritual growth and with empirical studies suggesting that crisis and disequilibrium are precursors to spiritual struggle (Fowler 1981, Holcomb \& Nonneman, 2004; Parks, 2000; Tisdell, 2003; Welch \& Koth, 2013). Similarly, Sanford's theory fits with research indicating that without enough support spiritual growth may be inhibited and students can get stuck in maladaptive behavior patterns (Bryant \& Astin, 2008; Faigin, 2013; Holcomb \& Nonneman, 2004).

Findings from service-learning research demonstrate the potential for this pedagogical method to offer both challenge and support. Prior studies have indicated that service-learning challenges can include exposure to diverse perspectives that do not fit with previously held perspectives (Astin, Vogelgesang, Ikeda, \& Yee, 2000; Eyler, Giles, Stenson, \& Gray, 2001; Kiely, 2005); exposure to complex social problems without easy solutions (Eyler \& Giles, 1999; Kiely, 2005); exposure to social problems that seem unjust (Kiely, 2005); and written reflection activities and class discussions that ask students to think critically about prior assumptions, values, or beliefs (Eyler et al., 2001; Eyler \& Giles, 1999; Fenzel \& Peyrot, 2005; Hatcher, Bringle, \& Muthiah, 2004; Kiely, 2005). To effectively process these challenges and integrate a new way of thinking into a student's being, support can manifest itself through reflection 
activities that provide the opportunity to process cognitive dissonance by connecting service experiences with course content (Astin, et al., 2000; Eyler et al., 2001; Fenzel \& Peyrot, 2005) or supportive relationships with faculty members, peers, or service site supervisors (Astin et al., 2000; Eyler \& Giles, 1999; Hatcher et al., 2004; Kiely, 2005). In this manner, service-learning presents the possibility for challenge and support to exist simultaneously within an academic context.

\section{Methods}

To further understand how service-learning can be utilized as a pedagogical tool fostering spiritual growth, this study addressed two research questions: (1) Which aspects of the service-learning experience relate to the occurrence of spiritual growth? (2) What roles do challenge and support play in the process of spiritual growth? The study addressed these questions through an explanatory, sequential, mixedmethods approach that incorporated two distinct phases. First, quantitative data were collected and analyzed to understand overall trends among study participants. These results were then used to inform the second qualitative phase of the study which sought to offer greater depth of understanding to the findings from the quantitative phase (Creswell \& Plano Clark, 2011).

\section{Study Participants}

Study participants were drawn from the Boston College PULSE Program for Service-Learning, a yearlong academic program integrating 10 to 12 hours of weekly service with an interdisciplinary philosophy and theology course. Boston College requires all students to fulfill core requirements in philosophy and theology, and the PULSE program is one avenue by which this core requirement can be met. Therefore, the program includes students from a wide variety of academic backgrounds, with varying interest in philosophy and theology. The vast majority of students participate in PULSE during their sophomore year.

Of the 272 study participants in the quantitative strand, $36 \%$ were male and $64 \%$ were female. The sample was 69.9\% White/Caucasian, 17\% Asian American/Asian, 12.5\% Hispanic/Latino/a, and 5.5\% African American/Black. Regarding religious preference, $60 \%$ of the participants self-identified as Catholic, 24.3\% non-religious, 3.3\% Jewish, and 2.9\% Presbyterian (all other religions were represented by fewer than 8 students in the sample). Although nearly all study participants (97.8\%) were previously involved in community service, $84.6 \%$ had not previously taken a service-learning course. Study participants served in more than 50 different sites and were enrolled in 14 different PULSE classes taught by nine different professors.

\section{Data Collection and Analysis}

The quantitative strand of the study included a pre-service and post-service survey that was emailed to all PULSE students in conjunction with the program's annual assessment process during the 2012-2013 academic year. Among the total 361 students in the 2012-2013 PULSE Program, 272 students completed both the pre- and post-survey for a total response rate of $75 \%$. Eleven survey respondents whose results indicated an extremely high or low spiritual growth level participated in semi-structured interviews.

Based upon findings from previous service-learning research (Astin et al., 2000; Eyler et al., 2001; Eyler \& Giles, 1999; Fenzel \& Peyrot, 2005; Hatcher et al., 2004; Kiely, 2005) as well as Sanford's $(1962,1966,1967)$ theoretical framework of challenge and support, quantitative variables were developed to measure aspects of the service-learning experience. In the post-survey, study participants responded to their level of agreement with each of the variables listed in Table 1. 
Table 1. Independent Variables/PULSE Components

\section{Variable}

- I observed unfair human suffering at my PULSE placement. ${ }^{\mathrm{b}}$

- My PULSE placement experience challenged me to think critically about my assumptions, values, and/or beliefs. ${ }^{\mathrm{c}}$

- Class journaling/reflective writing challenged me to think critically about my assumptions, values, and/or beliefs. ${ }^{\mathrm{a}}$

- There was a diversity of perspectives expressed in my PULSE class and discussion group. ${ }^{\mathrm{a}}$

- The problems that caused people at my placement to need social services were frequently the result of circumstances beyond their control. $^{\mathrm{b}}$

- PULSE exposed me to diverse viewpoints that challenged me to think differently. ${ }^{\mathrm{c}}$

- This course exposed me to diverse perspectives that did not fit with my prior opinions and assumptions. ${ }^{\mathrm{c}}$

- I built caring relationships with those served at my placement. ${ }^{\mathrm{d}}$

- Class assignments challenged me to think critically about my assumptions, values, and/or beliefs. ${ }^{a}$

- Social problems are more complex to solve than I used to think. ${ }^{\mathrm{c}}$

- Those served at my PULSE placement faced unfairness in life. ${ }^{b}$

- The class discussions/reflection groups challenged me to think critically about my assumptions, values, and/or beliefs. ${ }^{\mathrm{a}}$

- Class discussions/reflection groups enabled me to connect what I was observing in my placement with what I was studying in class. ${ }^{\mathrm{a}}$

- I felt supported by my PULSE supervisor(s). ${ }^{\mathrm{d}}$

- A supportive community formed among those in my PULSE discussion group. ${ }^{\mathrm{e}}$

- The class readings helped me to make sense of what I was observing in my placement. ${ }^{a}$

- The service component of this course was well integrated with the academic coursework. ${ }^{\mathrm{a}}$

- I felt supported by other students at my placement. ${ }^{\mathrm{d}}$

- I felt supported by my PULSE professor. ${ }^{a}$

- I felt supported by others students in my class. ${ }^{e}$

- I felt supported by my PULSE Council Member.

${ }^{\mathrm{a}}$ Variable included in the Classroom Experience scale

${ }^{b}$ Variable included in the Witnessing Injustice scale

${ }^{c}$ Variable included in the Eye Opening scale

${ }^{\mathrm{d}}$ Variable included in the Relationships at Service Site scale

${ }^{\mathrm{e}}$ Variable included in the Support of Peers in Class scale

A literature review led to a conceptualization of spirituality as comprising the following dimensions: (1) being engaged in a dynamic process of inner reflection to better understand oneself and the meaning and purpose of one's life; (2) living out one's personal philosophy of life with authenticity and integrity; (3) seeking a connection to and relationship with a higher power; and (4) believing in the interconnectedness of humanity and a related desire to be of service to others (Astin et al., 2011b; Braskamp, Trautvetter, \& Ward, 2006; Love \& Talbot, 1999; Roehlkeptatian et al., 2008).

Specific variables related to these spirituality dimensions from the College Students' Beliefs and Values survey (Astin et al., 2011a, 2011b) were utilized in both the pre- and post-surveys to measure the overall spiritual orientation of study participants (see Table 2). The Spiritual Orientation scale $(\alpha=.932)$ 
was created for this study by totaling results from all of the CSBV spirituality indicators utilized in the surveys except those related to spiritual struggle. Because of the important role spiritual struggle is theorized to play in facilitating spiritual growth, a separate Spiritual Struggle scale $(\alpha=.779)$ incorporated indicators from the CSBV pertaining to questioning one's religious or spiritual background and beliefs (see Table 3).

Table 2. Spiritual Orientation Variables $(\alpha=.932)$

\section{Variable}

- Being on a spiritual quest ${ }^{\mathrm{a}}$

- Integrating spirituality into my life ${ }^{b}$

- Believing in the sacredness of life ${ }^{\mathrm{a}}$

- People can reach a higher spiritual plane of consciousness through meditation or prayer ${ }^{\mathrm{c}}$

- Seeking out opportunities to grow spiritually ${ }^{\mathrm{b}}$

- Having an interest in spirituality ${ }^{\mathrm{a}}$

- Having a spiritual experience while: Engaging in athletics ${ }^{\mathrm{d}}$

- Participating in a musical or artistic performance ${ }^{\mathrm{d}}$

- $\quad$ Meditating ${ }^{\mathrm{d}}$

- Viewing a great work of art ${ }^{\mathrm{d}}$

- Listening to beautiful music ${ }^{\mathrm{d}}$

- Witnessing the beauty and harmony of nature ${ }^{\mathrm{d}}$

- Having discussions about the meaning of life with my friends ${ }^{\mathrm{e}}$

- Seeking beauty in my life ${ }^{b}$

- Attaining wisdom ${ }^{\mathrm{b}}$

- Developing a meaningful philosophy of life ${ }^{b}$

- Becoming a more loving person ${ }^{\mathrm{b}}$

- Finding answers to the mysteries of life ${ }^{\mathrm{b}}$

- Attaining inner harmony ${ }^{\mathrm{b}}$

- Searching for meaning/purpose in life $\mathrm{e}^{\mathrm{e}}$

- Close friends are searching for meaning/purpose in life ${ }^{\mathrm{f}}$

- Influencing the political structure ${ }^{b}$

- Becoming a community leader ${ }^{\mathrm{b}}$

- Love is at the root of all the great religions ${ }^{\mathrm{c}}$

- Trying to change things that are unfair in the world ${ }^{\mathrm{e}}$

- Having an interest in different religious traditions ${ }^{\mathrm{a}}$

- Feeling a strong connection to all humanity ${ }^{\mathrm{a}}$

- All life is interconnected ${ }^{\mathrm{c}}$

- Improving the human condition ${ }^{\mathrm{b}}$

- Believing in the goodness of all people ${ }^{a}$

- Influencing social values ${ }^{b}$ 


\section{Variable}

- Helping to promote racial understanding ${ }^{\mathrm{b}}$

- Reducing pain and suffering in the world ${ }^{b}$

- Helping others who are in difficulty ${ }^{b}$

- Improving my understanding of other cultures and countries ${ }^{\mathrm{b}}$

- Becoming involved in programs to clean up the environment ${ }^{b}$

- Most people can grow spiritually without being religious ${ }^{\mathrm{c}}$

- We are all spiritual beings ${ }^{\mathrm{c}}$

- Nonreligious people can lead lives that are just as moral as those of religious believers ${ }^{\mathrm{c}}$

- Accepting others as they are ${ }^{\mathrm{e}}$

- My spiritual/religious beliefs: Provide me with strength, support and guidance ${ }^{\mathrm{c}}$

- Lie behind my whole approach to life ${ }^{\mathrm{c}}$

- Help to define the goals I set for myself $f^{\mathrm{c}}$

- Have helped me develop my identity ${ }^{\mathrm{c}}$

- I gain spiritual strength by trusting in a Higher Power ${ }^{\mathrm{c}}$

- Prayed $^{\mathrm{d}}$

- Desiring a sense of connection with God/a Higher Power ${ }^{\mathrm{a}}$

${ }^{a}$ Extent to which the variable describes the respondent. $1=$ Not at all; $2=$ To some Extent; $3=$ To a great extent. ${ }^{\mathrm{b}}$ Importance to the respondent. 1 = Not important; 2 = Somewhat important; 3 = Very important; $4=$ Essential. ${ }^{c}$ Level of agreement with the statement. $1=$ Strongly disagree; $2=$ Disagree somewhat; $3=$ Agree somewhat; $4=$ Agree strongly.

${ }^{\mathrm{d}}$ Frequency of occurrence. $1=$ Not at all or Not applicable; $2=$ Occasionally; $3=$ Frequently.

${ }^{\mathrm{e}}$ Extent to which the respondent engages in the activity. $1=$ Not at all; $2=$ To some extent; $3=$ To a great extent. ${ }^{\mathrm{f}} 1=$ None $; 2=$ Some; $3=$ Most 4 = All.

Table 3. Spiritual Struggle Variables $(\alpha=.779)$

\section{Variable}

- Feeling unsettled about spiritual/religious matters ${ }^{\mathrm{a}}$

- Feeling disillusioned with my religious upbringing ${ }^{\mathrm{b}}$

- Questioned my religious/spiritual beliefs ${ }^{\mathrm{a}}$

- Disagreed with my family about religious matters ${ }^{\mathrm{a}}$

- $\quad$ Struggled to understand evil, suffering, and death ${ }^{\mathrm{a}}$

- Felt distant from God ${ }^{\mathrm{a}}$

- Felt angry with God $^{\mathrm{a}}$

${ }^{a}$ Frequency of occurrence since entering college.

${ }^{\mathrm{b}}$ Extent to which the variable describes the respondent.

To better address the broader question of how a service-learning experience might facilitate spiritual growth, variables were categorized in two different ways. First, to consider the theoretical perspective of 
challenge and support, summative scales of Total Support and Total Challenge were created by adding all variables that related to each of these components. The Total Support scale included the independent variables that measured whether students received support through relationships and/or support through integration of the classroom material with the service experience. Because some of these indicators had no potential relationship to one another, reliability analysis was not conducted on the Total Support scale. The Total Challenge scale $(\alpha=.839)$ focused on the ways in which students were challenged to think critically about their own perspectives, challenged to see complexity in the world, challenged through their relationships with those suffering unfairly, and challenged through their exposure to diverse perspectives. Exploratory factor analysis with varimax rotation then led independent variables to be categorized into the following service-learning components: Class Experiences $(\alpha=.885)$, an Eye Opening Experience $(\alpha=.767)$, Witnessing Injustice $(\alpha=.635)$, Relationships at Service Sites $(\alpha=.509)$, and Support of Peers in Class $(\alpha=.661)$ (see Table 1 for details about which variables were associated with which category.).

Hierarchical multiple regression was conducted to consider which categories of independent variables served as predictors of spiritual growth as measured by comparing pre- and post-test scores in the Spiritual Orientation and Spiritual Struggle scales. The following input characteristics were statistically controlled in the regression models: pre-survey results, gender, ethnicity, religious background, academic school within Boston College, and prior service-learning experience.

The quantitative survey was followed by semi-structured interviews in the late spring of 2013. Interview questions were determined after preliminary analysis of quantitative results in order to assess which topics needed further explanation. The interview questions were consistent with the overarching research questions and explored the role that each of the following may have played in spiritual growth: group reflection discussions, written reflection, relationships, cognitive dissonance, a high-quality service experience, and connection between coursework and the service experience. Study participants were also asked about demographic and personal characteristics that might have influenced the possibility for spiritual growth, including prior community service and service-learning experience, religious background, and family background.

Interviewees were selected based upon quantitative results in combination with demographic variables. Six students were chosen because they exhibited a high degree of pre- to post-test change in spirituality variables, while five students were chosen because they exhibited a neutral to negative degree of spiritual change in quantitative measures. Interviewees represented a variety of service sites, PULSE classes, and demographic variables.

All interviews were recorded and transcribed. Data analysis began by reading interview transcriptions in their entirety to note any recurring ideas. These notes were used to classify and code data in NVivo software. Codes were then combined into themes that were analyzed in light of the research questions. To increase validity, long-term observation, member checking, peer review, and triangulation were incorporated into the analysis (Creswell, 2007).

\section{Results}

Quantitative results indicated that students did grow spiritually (as measured by positive change in Spiritual Orientation) during the PULSE experience. Nearly eighty percent (77.6\%) of PULSE students had a higher score in Spiritual Orientation on the post-survey than the pre-survey. Consistent with Sanford's $(1962,1966,1967)$ student development theory, qualitative and quantitative aspects of this study pointed toward both challenge and support relating to the occurrence of spiritual growth.

In the quantitative study, the Total Challenge and Total Support scales were statistically significant predictors of change in Spiritual Orientation after controlling for demographic variables and pre-test scores (see Tables 4 and 5). In analyzing specific service-learning components, quantitative results pointed toward the Classroom Experience, an Eye-Opening Experience, Witnessing Injustice, and Support of Peers in Class as being statistically significant predictors of increased Spiritual Orientation in 
at least one regression model when factoring in PULSE components one at a time. Class Experience and Witnessing Injustice were the strongest predictors as both remained significant when controlling for other PULSE components as illustrated in Table 6. Witnessing Injustice and an Eye-Opening Experience were statistically significant predictors of spiritual struggle after controlling for demographic variables and other PULSE components (see Table 7). Relationships at Service Sites was a negative predictor of spiritual struggle.

Table 4. Hierarchical Multiple Regression Predicting Increase in Spiritual Orientation by Total Challenge

\begin{tabular}{lrr}
\hline Variable & Model 1 & Model 2 \\
\hline Pre-Test & $.644^{* * *}$ & $.576^{* * *}$ \\
Gender & .085 & .029 \\
School & .049 & .028 \\
Prior Service-learning & -.004 & .013 \\
Jewish & .000 & -.004 \\
Presbyterian & $.120^{*}$ & $.136^{*}$ \\
Roman Catholic & $.203^{*}$ & $.193^{*}$ \\
None & -.024 & -.025 \\
African American/Black & $.144^{*}$ & $.129 *$ \\
Asian American/Asian & .109 & .098 \\
Mexican American/Chicano & -.029 & -.042 \\
Puerto Rican & .013 & .048 \\
Other Latino & .053 & .012 \\
White/Caucasian & -.016 & -.037 \\
Total Challenge & & $.272^{* * *}$ \\
\hline
\end{tabular}

Note. Numbers are Betas. ${ }^{* * *} \mathrm{p}<.001$, two-tailed $* * \mathrm{p}<.01$, two-tailed $* \mathrm{p}<.05$, two-tailed

Due to low numbers in the sample and lack of statistical significance, the following variables included in the regression model are not listed in this table: Baptist, Buddhist, Eastern Orthodox, Episcopalian, Lutheran, Methodist, Muslim, Nondenominational, Unitarian Universalist, United Church of Christ, Native Hawaiian/Pacific Islander, Middle Eastern. 
299 | International Journal of Research on Service-Learning and Community Engagement

Table 5. Hierarchical Multiple Regression Predicting Increase in Spiritual Orientation by Total Support

\begin{tabular}{lrr}
\hline Variable & Model 1 & Model 2 \\
\hline Pre-Test & $.641 * * *$ & $.592 * * *$ \\
Gender & .080 & .055 \\
School & .049 & .044 \\
Prior Service-Learning & .008 & .022 \\
Jewish & -.002 & -.043 \\
Presbyterian & $.121 *$ & $.127 *$ \\
Roman Catholic & $.204 *$ & .169 \\
None (Religious Affiliation) & -.017 & -.033 \\
African American/Black & $.144 *$ & .107 \\
Asian American/Asian & .100 & .084 \\
Mexican American/Chicano & -.031 & -.053 \\
Puerto Rican & .014 & .064 \\
Other Latino & .050 & .006 \\
White/Caucasian & -.014 & -.055 \\
Total Support & & $.260 * * *$ \\
\hline
\end{tabular}

Note. Numbers are Betas. ${ }^{* * *} \mathrm{p}<.001$, two-tailed $* * \mathrm{p}<.01$, two-tailed $* \mathrm{p}<.05$, two-tailed

Due to low numbers in the sample and lack of statistical significance, the following variables included in the regression model are not listed in this table: Baptist, Buddhist, Eastern Orthodox, Episcopalian, Lutheran, Methodist, Muslim, Nondenominational, Unitarian Universalist, United Church of Christ, Native Hawaiian/Pacific Islander, Middle Eastern. 
Table 6. Hierarchical Multiple Regression Predicting Increase in Spiritual Orientation by PULSE Components

\begin{tabular}{|c|c|c|c|c|c|c|}
\hline Variable & Model 1 & Model 2 & Model 3 & Model 4 & Model 5 & Model 6 \\
\hline Pre-Test & $.644^{* * *}$ & $.610^{* * *}$ & $.609 * * *$ & $.592^{* * *}$ & $.578^{* * *}$ & $.559 * * *$ \\
\hline Gender & .085 & .060 & .057 & .040 & .025 & .027 \\
\hline School & .049 & .043 & .045 & .039 & .042 & .029 \\
\hline Prior Service-learning & -.004 & .000 & .007 & .014 & .015 & .011 \\
\hline Jewish & .000 & -.012 & -.017 & -.013 & -.001 & -.025 \\
\hline Presbyterian & $.120^{*}$ & $.113^{*}$ & .107 & $.119 *$ & $.134 *$ & $.139 *$ \\
\hline Roman Catholic & $.203 *$ & $.199 *$ & $.184 *$ & $.193 *$ & $.212 *$ & $.182 *$ \\
\hline None & -.024 & -.056 & -.058 & -.041 & -.037 & -.047 \\
\hline African American/Black & $.145^{*}$ & .110 & .108 & .109 & .110 & .105 \\
\hline Asian American/Asian & .109 & .089 & .087 & .093 & .092 & .081 \\
\hline Mexican American/Chicano & -.029 & -.046 & -.046 & -.042 & -.044 & -.059 \\
\hline Puerto Rican & .013 & .033 & .036 & .039 & .050 & .078 \\
\hline Other Latino & .053 & .021 & .016 & .012 & .007 & -.009 \\
\hline White/Caucasian & -.016 & -.092 & -.084 & -.078 & -.096 & -.087 \\
\hline Peer Support & & $.164 * * *$ & $.142 * *$ & $.123 *$ & $.108^{*}$ & .067 \\
\hline $\begin{array}{l}\text { Relationships at Service } \\
\text { Sites }\end{array}$ & & & .089 & .056 & .031 & .010 \\
\hline Eye Opening Experience & & & & $.124 *$ & .073 & .006 \\
\hline Witnessing Injustice & & & & & $.154 * *$ & $.135^{*}$ \\
\hline Class Experience & & & & & & $.196^{* * *}$ \\
\hline
\end{tabular}

Note. Numbers are Betas. $* * * \mathrm{p}<.001$, two-tailed $* * \mathrm{p}<.01$, two-tailed $* \mathrm{p}<.05$, two-tailed

Due to low numbers in the sample and lack of statistical significance, the following variables included in the regression model are not listed in this table: Baptist, Buddhist, Eastern Orthodox, Episcopalian, Lutheran, Methodist, Muslim, Nondenominational, Unitarian Universalist, United Church of Christ, Native Hawaiian/Pacific Islander, Middle Eastern.

Table 7. Hierarchical Multiple Regression Predicting Increase in Spiritual Struggle by PULSE Components

\begin{tabular}{lrrrrrr}
\hline Variable & Model 1 & Model 2 & Model 3 & Model 4 & Model 5 & Model 6 \\
\hline Pre-Test & $.589^{* * *}$ & $.590^{* * *}$ & $.596^{* * *}$ & $.588^{* * *}$ & $.582^{* * *}$ & $.582^{* * *}$ \\
Gender & .046 & .036 & .039 & -.002 & -.018 & -.018 \\
School & -.002 & -.004 & -.004 & -.019 & -.016 & -.017 \\
Prior Service-learning & $-.127^{*}$ & $-.126^{*}$ & $-.132^{*}$ & $-.118^{*}$ & $-.117^{*}$ & $-.118^{*}$ \\
Baptist & $-.257^{* * *}$ & $-.253^{* * *}$ & $-.263^{* * *}$ & $-.229^{* * *}$ & $-.241^{* * *}$ & $-.241^{* * *}$
\end{tabular}


301 | International Journal of Research on Service-Learning and Community Engagement

$\begin{array}{lrrrrrr}\text { Jewish } & -.058 & -.061 & -.058 & -.048 & -.036 & -.037 \\ \text { Presbyterian } & .034 & .030 & .035 & .055 & .066 & .066 \\ \text { Roman Catholic } & .034 & .031 & .043 & .053 & .067 & .065 \\ \text { None (Rel. Affiliation) } & -.048 & -.057 & -.055 & -.020 & -.017 & -.017 \\ \text { African American/Black } & .052 & .043 & .045 & .050 & .052 & .052 \\ \text { Asian American/Asian } & -.096 & -.100 & -.099 & -.082 & -.081 & -.081 \\ \text { Mexican American/Chicano } & -.005 & -.011 & -.010 & -.003 & -.006 & -.007 \\ \text { Puerto Rican } & -.045 & -.040 & -.043 & -.039 & -.029 & -.028 \\ \text { Other Latino } & .022 & .014 & .017 & .014 & .013 & .012 \\ \text { White/Caucasian } & -.060 & -.080 & -.087 & -.064 & -.076 & -.076 \\ \text { Peer Support } & & .047 & .066 & .020 & .004 & .002 \\ \text { Relationships at Service } & & & -.073 & -.141^{*} & -.162^{* *} & -.163^{* *} \\ \text { Sites } & & & & & & .208^{* *} \\ \text { Eye Opening } & & & & .256^{* * *} & .206^{* *} \\ \text { Witnessing Injustice } & & & & & .138^{*} & .137^{*} \\ \text { Class Experience } & & & & & & .008\end{array}$

Note. Numbers are Betas. $* * * \mathrm{p}<.001$, two-tailed $* * \mathrm{p}<.01$, two-tailed $* \mathrm{p}<.05$, two-tailed Due to low numbers in the sample and lack of statistical significance, the following variables included in the regression model are not listed in this table: Buddhist, Eastern Orthodox, Episcopalian, Lutheran, Methodist, Muslim, Nondenominational, Unitarian Universalist, United Church of Christ, Native Hawaiian/Pacific Islander, Middle Eastern.

In the qualitative portion of the study, there were consistent differences between the PULSE experiences of high-growth (HG) interviewees and neutral/negative-growth (NNG) interviewees that paralleled quantitative findings. Students with lower levels of spiritual growth simply were not challenged by the service experience or the classroom experience to the same degree as students who exhibited higher levels of spiritual growth. While supportive relationships seemed to be readily available to nearly all interviewees and were mentioned as important to all, students with higher levels of spiritual growth also discussed the benefit of finding support through the integration of the class content with the service experience.

While none of the NNG interviewees discussed the ways in which PULSE differed from other types of service they had done previously, five of the six HG interviewees mentioned this. The HG interviewees described how their service through PULSE involved different populations, was more direct, was more frequent, and involved more reflection.

All five of the NNG interviewees discussed some structural or logistical aspect of their service experience that was less than ideal (e.g., having little "work" to do at the service site), but only one of the HG interviewees did. Yet, while the HG interviewee found such administrative issues to be minor nuisances, they became more of a central focus for most of the NNG interviewees. That is, these structural or logistical issues hindered the development of relationships between students and the clients at service sites among all five of the NNG interviewees. In sharp contrast, five of the six HG interviewees spoke extensively about the strong relationships they had built with clients at their service sites. The weaker relationships developed among NNG interviewees meant that they were also less likely to engage in conversations with clients. Only two of the five NNG interviewees discussed stories they had heard or new perspectives that arose during conversations at their service site. On the contrary, five of the six HG interviewees mentioned the importance of stories. These stories had an overwhelming 
emotional impact on five of the six HG interviewees, but only on one of the five NNG interviewees. While all six HG students indicated that their PULSE experience opened their eyes, broke down stereotypes, or enabled them to see that the world is more complex than previously thought, only one of the five NNG interviewees did so.

Perhaps as a result of having a less engaging service experience, four of the five NNG interviewees did not indicate they had been challenged to think critically about their assumptions, beliefs, or values through their PULSE class experience. By contrast, all six of the HG interviewees found that their PULSE class challenged them to think critically in this manner. Similarly, four of the five NNG interviewees did not find their service and class experiences to be well connected, while four of the six HG interviewees specifically mentioned that they found the two to be integrated. Only one of the NNG students felt he did not have any relationships through PULSE to which he could turn for support. The other 10 students felt they had supportive relationships with either their PULSE professor, other students in their class, other students at their service site, their PULSE council member, or their service site supervisor.

It is also noteworthy that three of the five NNG interviewees made specific statements demonstrating an unlikelihood that they could have changed spiritually through PULSE. Two of these students indicated this was because they had already thought about the types of spiritually related questions that could arise through PULSE. However, five of the six HG interviewees demonstrated an openness to growth through the PULSE experience.

Qualitative results also leant description and depth to the following concepts from the quantitative portion of the study: witnessing injustice, having one's eyes opened, being challenged through class experiences, spiritual struggle, and the support received through these challenges.

The following quotations from interviewees exemplify the concept of being challenged through witnessing injustice:

- I've started really questioning how it's fair that some of these people, who are just amazing people, would be able to do amazing things if they had the resources, but since they don't, they're not going to. I've also been questioning why I was so fortunate to have been given all these resources.... It really makes me think about what's fair and what's not fair, and how it's so hard to be the one that breaks out, goes to college, and moves on. All of these kids want to go to college, but their education levels are below the year they're actually in. Even though [one of the students being tutored] is in $10^{\text {th }}$ grade, she couldn't even do multiplication.... It's been amazing to think about how someone's location in the world, how they're raised, and what schools they go to, really affect who they can be.

- There was a woman I was talking to last night whose son had just been shot and killed, and she was incredibly upset about that. It was hard to hear her talking about how she didn't really have time to grieve because she was worried about paying bills and other things because she has so many things that she has to take care of. She was actually employed, but it was a job that didn't really pay enough for you to grow or sustain yourself very easily.... Listening to her talk about it was one of those things where I didn't even know what to say to console her. What do you say to someone who just lost their child? Especially someone who is still so stressed about staying alive and sheltered that they can't even properly focus on their pain.

Along with being challenged by witnessing injustice at their service sites, students were also challenged to think from a new perspective through class readings, class discussions, and written assignments. The following quotations describe challenges students faced in class:

- A lot of the reflections we did, like our written reflections and even discussions, would bring up things I had never really thought about before. 
- I loved the classroom dynamic because we got a lot of readings, and he expected us to really know the readings and to think critically about them ... he has us read really thought-provoking material.

- [The professor will] make a point, and then he'll kind of counter it to really get you to make sure that what you're saying is what you believe. He does kind of challenge what you believe and what you value.

- Some of the stories that people told [in discussion groups] were very intense and were things that you couldn't see and not react to and not think about after the fact.

- [The final class paper was the] most challenging thing [as we argued] the purpose of your life ...Who are we? Where do we come from? How should we live? For what reason?

"Eye opening" was the phrase HG interviewees used most consistently to describe the PULSE experience. Students spoke passionately about how their experiences did not conform to preconceived notions and had opened their eyes in unexpected ways. The following interviewee comments illustrate how students described this aspect of PULSE:

- I was able to see the different ways that kids grow up in this country compared to my own town and childhood, and that really just took me back. It was really interesting and very eye-opening for me.

- My preconceptions about people with drug abuse were totally wrong ... I just thought that a lot of times people just brought it on themselves. I always thought that addiction was a matter of choice, but after listening to their stories, I realized that when you're in recovery and you go home back to a place where everyone is doing that, it's very difficult, especially if all of your friends do that. I learned about their struggles and what they go through. It's just amazing.

- [The community service site] really opened my eyes to what it means to be homeless and what it means to be poor ... They were such hard-working women, and the things that they were talking about made me see that they were people. I never would've admitted it before, but I realized that I definitely did have stigmas towards what it means to be homeless. I always thought that there had to be something different about them, but for so many of those women it's just their circumstances.

- Some of my other classmates who didn't grow up in urban neighborhoods like mine, it was definitely more eye-opening for them. It's still eye-opening to me.

The spiritual struggle experienced as a result of participating in the PULSE Program was described in emotional ways by nearly all of the HG interviewees:

- I remember one day calling my mom and asking her, "What are we doing?"... I was asking her things like, "Why are we believing these things?" ... She said ..."This is the way that you are brought up and this is our faith." She was actually being kind of closed-minded.

- $\quad$ PULSE] has made me question everything about God and my religion. I like that it's challenging my faith, but at the same time it can be bothersome for me because I don't know what to think anymore.

- $\quad[\mathrm{I}$ 'm] questioning my own faith and what it even means to have faith.... I'm still super confused about any notion of a higher power...I'm definitely still struggling.

In the midst of these challenges, students described receiving support from their professors, classmates, community-service site supervisors, other PULSE students serving at their site, and PULSE student leaders, and integrating course material with the service experience. 
- Our weekly discussions really allowed me to open up and question a lot of things that relate to my spirituality. I also feel as though becoming so close as a class and with [my professor] has created a bond that I cannot help but feel as somewhat spiritual and good.

- [The professor] would make sure that every single one of us got to talk about our [service sites] ... she made it very easy for us to email her or go to her office hours.... She was very supportive and really insightful.

- The reflections were my favorite writing activities where we would take a reading and apply our experiences to our placement; those were very beneficial.

\section{Discussion}

Overall, quantitative and qualitative results of this study indicated that challenge and support did indeed relate to the occurrence of spiritual growth. Integrating these results with Sanford's $(1962,1966,1967)$ student development theory, spiritual development theories, and the findings from prior service-learning studies leads to a conceptual model (see Figure 1) describing how spiritual development may occur during the service-learning experience.

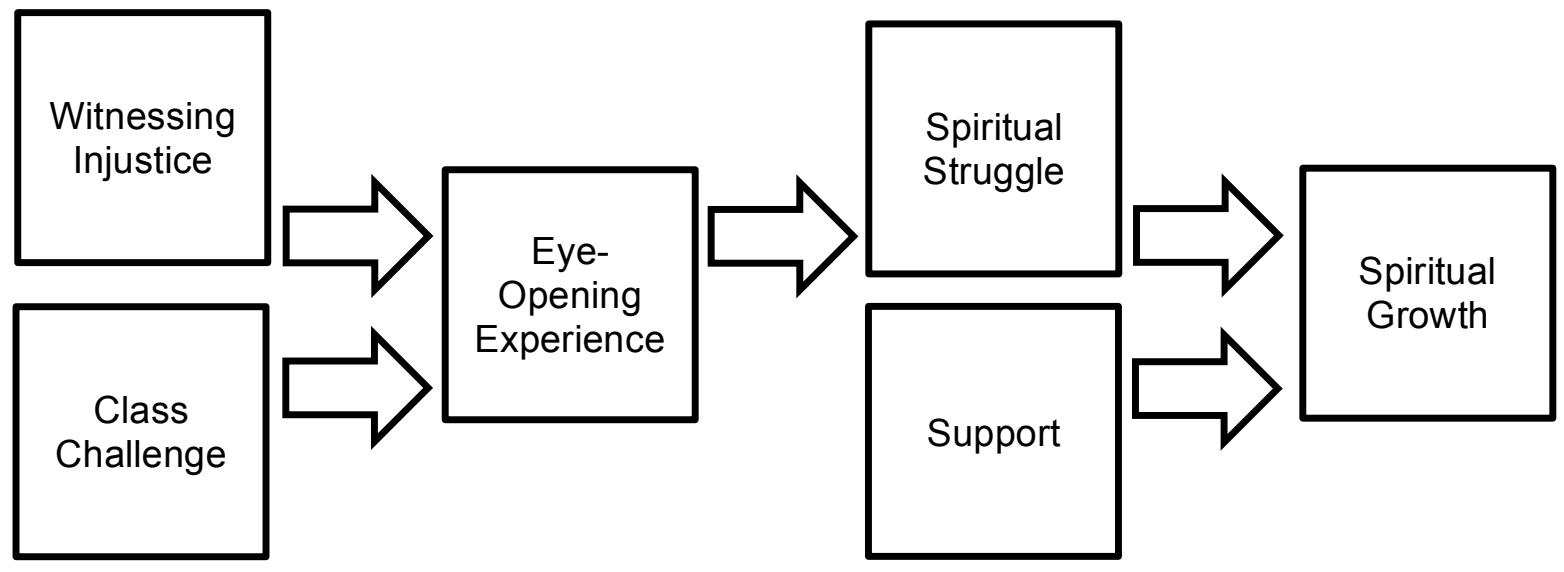

Figure 1. Conceptualization of how spiritual growth may occur through service-learning.

According to this model, the spiritual growth process begins when a student is challenged by witnessing the impacts of injustice on the lives of individuals he or she gets to know at the service site. As the student is being challenged by social justice issues witnessed first-hand through service, his or her prior assumptions about the world are simultaneously challenged in class as a result of learning about the service experiences and diverse perspectives of other students, exposure to class readings that present new and challenging perspectives, and questions posed by professors in class discussions and assignments about what he or she believes and why (including questions about faith, purpose, meaning, and fairness).

In this study, the combination of these challenges opened students' eyes to the idea that the world is not exactly what they believed it to be-in a very fundamental way. Many of the interviewees revealed that, prior to their participation in the PULSE Program, they "knew" people living in poverty mainly through stereotypes - which often blame the poor and perpetuate beliefs that the poor are fundamentally inferior to those who have been successful in traditional terms. Yet, such assumptions are difficult to maintain when first-hand experiences do not conform to stereotypes. Students were humbled to discover deep resiliency, fortitude, and wisdom in those they previously believed to be inferior or deficient. These challenges led students to question the certainty of all deeply held beliefs-including those associated with suffering, spirituality, religion, and God. Being emotionally overwhelmed by thinking about these complex questions and being challenged to view the world from a new perspective, drove interviewees 
toward inner reflection in an effort to reduce disequilibrium and make sense of the experience. Throughout this difficult time of challenge and reflection, the class framework and supportive relationships helped struggling students to process this dissonance in a healthy manner leading to growth rather than stagnation.

Multiple regression analyses have demonstrated that each component of this model is a statistically significant predictor of the component that follows and that mediation is occurring in the proposed manner (see Sterk Barrett, 2015). In other words, Witnessing Injustice and Class Challenge (a sub-set of the Class Experience scale) have an indirect effect on Spiritual Struggle, which is mediated through an Eye-Opening Experience. In turn, an Eye-Opening Experience has an indirect effect on growth in Spiritual Orientation through Spiritual Struggle.

The central role of an Eye-Opening Experience in this model leads naturally to the question of whether students from varying backgrounds experience spiritual growth to varying degrees. In other words, are some students less likely to have their eyes opened and, therefore, less likely to grow spiritually? In reviewing the hierarchical multiple regression results of this study, there were surprisingly few differences regarding students' backgrounds. Gender and school of academic study, for instance, had no statistically significant relationship to the occurrence of spiritual growth. Ethnic background had no statistically significant relationship to change in Spiritual Orientation except among AfricanAmerican/Black students (who exhibited higher levels of growth) in the Total Challenge regression. Most notable was the consistently higher change in Spiritual Orientation among Presbyterians and Roman Catholics (the only two Christian groups with more than eight students in the study sample). It appears that Boston College's Catholic identity may have led class discussions of spirituality to resonate more for Christian students than non-Christian students. One interviewee with no religious background explained the difficulty she had in understanding some class discussions because the professor "would assume that everyone has some Catholic background." Perhaps her experience was shared by other non-Christian students in the class.

\section{Limitations}

The PULSE Program and Boston College itself possess unique aspects that may limit the generalizability of the study findings. Specifically, PULSE occurs over a full academic year, includes more hours of weekly service than typical service-learning programs, and is focused on the disciplines of philosophy and theology. Boston College is unique in that it is a highly selective Catholic higher education research institution.

Another limitation of this study is the way in which the quality of relationships at service sites was measured quantitatively. While interviewees consistently discussed the importance of these relationships and how they changed with time, the quantitative results were not consistent with qualitative results in this regard. The lack of statistical significance in these results may be due to the contradictory nature (in terms of challenge and support) of the variables included in this factor. While relationships at the service site (especially those with site supervisors) may have enabled students to feel supported, forming caring relationships with those facing injustice and suffering would most likely have been challenging for students. Thus, it is recommended that future studies incorporate additional (and more nuanced) variables to better explore the importance of these relationships and how such relationships grow in reciprocity over time.

\section{Conclusion}

This study explored ways in which spiritual development can be fostered among undergraduates through service-learning. This is especially important given the disparity between students' desire for spiritual growth and opportunities for spiritual growth to occur in the classroom context (Astin et al., 2004). Furthermore, integrating opportunities for spiritual growth in the classroom has the potential to lead to 
other personal and societal benefits associated with spirituality (Astin et al., 2011b; Brandenberger \& Bowman, 2013; Kuh \& Gonyea, 2006; Nelms et al., 2007; Park \& Millora, 2010; Walker \& Dixon, 2002).

Study findings point toward important service-learning components that should be incorporated to maximize potential spiritual growth for students. First, it is essential to develop community partnerships that will enable students to interact with and build reciprocal relationships with individuals facing injustice so that possibilities exist to hear stories about or witness injustice. Indeed, through these stories and observations, students' stereotypes and assumptions about the world are challenged. In this eyeopening experience, a student realizes that his or her preconceptions about people living in poverty are not entirely accurate, and, therefore, the student's prior worldview is no longer sustainable. The resulting disequilibrium opens up the possibility for growth.

At the same time students' assumptions are being challenged through their service experience, class experiences should challenge students to think critically about assumptions and beliefs. This can be facilitated by hearing diverse perspectives in class discussions or class readings and asking students to consider, in class discussions and assignments, what they believe and why. Not surprisingly, Astin et al. (2011b) found that the greatest predictor of spiritual growth among undergraduates was whether a professor encouraged spiritual discussions in class.

As students face the disequilibrium associated with having their eyes opened and realize that their prior assumptions may be inaccurate, it is important that they have access to support through integration and through relationships. The effective integration of classroom material and service-learning can help students to make sense of their challenging experiences and process their feelings of disequilibrium. As demonstrated in previous research, this important integration can occur in class discussions, small-group reflections, journaling, and class reading and writing assignments (Astin et al., 2000; Eyler \& Giles, 1999; Hatcher et al., 2004). Students also need the opportunity to receive support through relationships. Indeed, relationships with peers and faculty members were found to be especially pertinent in this study as they have been in prior research (Astin et al., 2000; Eyler \& Giles, 1999; Kiely, 2005; Radecke, 2007).

\section{Acknowledgements}

The author would like to thank Dwight Giles, Jr., John Saltmarsh, Alyssa Rockenbach, and Mark Hallahan for their guidance with this study.

\section{Author Note}

Michelle Sterk Barrett, Donelan Office of Community-Based Learning, College of the Holy Cross.

\section{Correspondence}

Correspondence regarding this article should be addressed to Michelle Sterk Barrett, Director, Donelan Office of Community-Based Learning, College of the Holy Cross, P.O. Box 225A, 1 College Street, Worcester, MA 01610. Phone: (508) 793-3006. Email: msbarret@holycross.edu

\section{References}

Astin, A., Astin, H., \& Lindholm, J. (2004). Spirituality in higher education: A national study of college students' search for meaning and purpose summary of selected findings (2000-2003). Los Angeles: University of California Los Angeles, Higher Education Research Institute. Retrieved from http://www.heri.ucla.edu/publications-brp.php 
Astin, A., Astin, H., \& Lindholm, J. (2011a). Assessing students' spiritual and religious qualities. Journal of College Student Development, 52(1), 39-61.

Astin, A., Astin, H., \& Lindholm, J. (2011b). Cultivating the spirit: How college can enhance students' inner lives. San Francisco, CA: Jossey-Bass.

Astin, A. W., Vogelgesang, L. J., Ikeda, E. K., \& Yee, J. A. (2000). How service-learning affects students: Executive summary. Retrieved from http://gseis.ucla.edu/heri/publications-main.php

Brandenberger, J. W., \& Bowman, N.A. (2013). From faith to compassion? Reciprocal influences of spirituality, religious commitment, and prosocial development during college. In A. Bryant Rockenbach \& M. Mayhew (Eds.), Spirituality in college students' lives: Translating research into practice (pp. 121-137). New York, NY: Routledge.

Braskamp, L. A., Trautvetter, L. C., \& Ward, K. (2006). Putting students first: How colleges develop students purposefully. Bolton, MA: Anker Publishing Company.

Bryant, A. N., \& Astin, H. S. (2008). The correlates of spiritual struggle during the college years. Journal of Higher Education, 79(1), 1-27.

Cherry, C., De Berg, B., \& Porterfield, A. (2001). Religion on campus. Chapel Hill, NC:

University of North Carolina Press.

Chickering, A. W., Dalton, J. C., \& Stamm, L. (2006). Encouraging authenticity and spirituality in higher education. San Francisco, CA: Jossey-Bass.

Creswell, J. (2007). Qualitative inquiry and research design: Choosing among the five approaches. Thousand Oaks, CA: Sage Publishing.

Creswell, J., \& Plano Clark, V. (2011). Designing and conducting mixed methods research ( $2^{\text {nd }}$ ed.). Thousand Oaks, CA: Sage Publications.

Eyler, J., \& Giles, D., Jr. (1999). Where's the learning in service-learning? San Francisco, CA: JosseyBass.

Eyler, J., Giles, D., Jr., Stenson, C., \& Gray, C. (2001). At a glance: What we know about the effects of service-learning on college students, faculty, institutions and communities, 1993-2000 ( $3^{\text {rd }} \mathrm{ed}$.). Washington, DC: Corporation for National Service. Retrieved from http://servicelearning.org/filemanager/download/aag.pdf

Faigin, C. A. (2013). Informing effective psychospiritual interventions for college students: Identifying mediators in the relationship between spiritual struggles and substance use. In A. Bryant Rockenbach \& M. Mayhew (Eds.), Spirituality in college students' lives: Translating research into practice (pp. 170-187). New York, NY: Routledge.

Fenzel, L. M., \& Peyrot, M. (2005). Comparing college community participation and future service behaviors and attitudes. Michigan Journal of Community Service-learning, 12(1), 23-32.

Fowler, J. (1981). Stages of faith: The psychology of human development and the quest for meaning. San Francisco, CA: Harper San Francisco.

Hatcher, J., Bringle, R., \& Muthiah, R. (2004). Designing effective reflection: What matters to servicelearning? Michigan Journal of Community Service-learning, 11(1), 38-46.

Holcomb, G. L., \& Nonneman, A. J. (2004). Faithful change: Exploring and assessing faith development in Christian liberal arts undergraduates. New Directions for Institutional Research, 122, 93-103.

Kiely, R. (2005). A transformative learning model for service-learning: A longitudinal case study. Michigan Journal of Community Service-learning, 12(1), 5-22.

Kuh, G. D., \& Gonyea, R. M. (2006). Spirituality, liberal learning, and college student engagement. Liberal Education, 92, 40-47.

Love, P., \& Talbot, D. (1999). Defining spiritual development: A missing consideration for student affairs. NASPA Journal, 37, 361-376.

Lovik, E. (2010). The impact of organizational features and student experiences on spiritual development during the first year of college (Unpublished doctoral dissertation). Pennsylvania State University.

Nelms, L., Hutchins, E., Hutchins, D., \& Pursley, R. (2007). Spirituality and the health of college students. Journal of Religion and Health, 46(2), 249-265. 
Park, J. J., \& Millora, M. (2010). Psychological well-being for white, black, Latino/a, and Asian American students: Considering spirituality and religion. Journal of Student Affairs Research and Practice, 47(4), 445-461.

Parks, S. (2000). Big questions, worthy dreams: Mentoring young adults in their search for meaning, purpose, and faith. San Francisco, CA: Jossey-Bass.

Radecke, M. W. (2007). Service-learning and faith formation. Journal of College and Character, 8(5), 128.

Rendon, L. I. (2009). Sentipensante (sensing/thinking) pedagogy: Educating for wholeness, social justice and liberation. Sterling, VA: Stylus Publishing.

Roehlkepartain, E. C., Benson, P. L., Scales, P. C., Kimball, L., \& Ebstyne-King, P. (2008). With their own voices: A global exploration of how today's young people experience and think about spiritual development. Minneapolis, MN: Center for Spiritual Development in Childhood and Adolescence.

Sanford, N. (1962). Developmental status of the entering freshman. In N. Sanford (Ed.), The American college: A psychological and social interpretation of higher learning(pp. 253-282). New York: John Wiley \& Sons.

Sanford, N. (1966). Self and society: Social change and individual development. New York, NY: Atherton Press.

Sanford, N. (1967). Where colleges fail: A study of the student as a person. San Francisco, CA: JosseyBass.

Sterk Barrett, M. (2015). Fostering the spiritual development of undergraduates through service-learning (Unpublished doctoral dissertation). University of Massachusetts Boston. Retrieved from http://scholarworks.umb.edu/doctoral_dissertations/222/

Tisdell, E. J. (2003). Exploring spirituality and culture in adult and higher education. The Jossey-Bass higher and adult education series. San Francisco, CA: Jossey-Bass.

Walker, K. L., \& Dixon, V. (2002). Spirituality and academic performance among African American college students. Journal of Black Psychology, 28(2), 107-21.

Welch, M., \& Koth, K. (2013). A meta-theory of the spirituality of service-learning in higher education. Journal of College Student Development, 54(6), 612-627.

Yeh, T. L. (2010). Service-learning and persistence of low-income, first-generation college students: An exploratory study. Michigan Journal of Community Service-learning, 16(2), 50-65. 